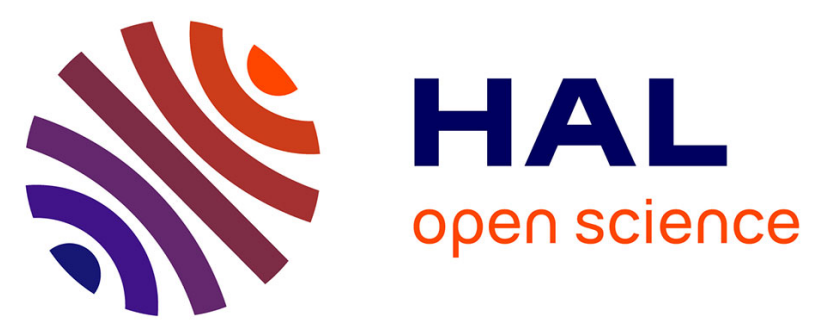

\title{
The use of total evaporation method using Channeltron electron multipliers by thermal ionization mass spectrometry for europium isotope ratio measurements on picogram sample amounts
}

S. Mialle, Alexandre Quemet, A. Ponvienne, A. Gourgiotis, M. Aubert, H. Isnard, F. Chartier

\section{To cite this version:}

S. Mialle, Alexandre Quemet, A. Ponvienne, A. Gourgiotis, M. Aubert, et al.. The use of total evaporation method using Channeltron electron multipliers by thermal ionization mass spectrometry for europium isotope ratio measurements on picogram sample amounts. International Journal of Mass Spectrometry, 2012, 309, pp.141-147. 10.1016/j.ijms.2011.09.014 . cea-03470721

HAL Id: cea-03470721

https://hal-cea.archives-ouvertes.fr/cea-03470721

Submitted on 8 Dec 2021

HAL is a multi-disciplinary open access archive for the deposit and dissemination of scientific research documents, whether they are published or not. The documents may come from teaching and research institutions in France or abroad, or from public or private research centers.
L'archive ouverte pluridisciplinaire HAL, est destinée au dépôt et à la diffusion de documents scientifiques de niveau recherche, publiés ou non, émanant des établissements d'enseignement et de recherche français ou étrangers, des laboratoires publics ou privés. 


\title{
The use of total evaporation method using Channeltron electron multipliers by thermal ionization mass spectrometry for europium isotope ratio measurements on picogram sample amounts
}

\author{
S. Mialle ${ }^{\mathrm{a}}$, A. Quémet ${ }^{\mathrm{a}}$, A. Ponvienne ${ }^{\mathrm{a}}$, A. Gourgiotis ${ }^{\mathrm{a}}$, M. Aubert ${ }^{\mathrm{a}}$, H. Isnard ${ }^{\mathrm{a}, *}$, F. Chartier $^{\mathrm{b}}$ \\ a Commissariat à l'Energie Atomique, Saclay, DEN/DPC/SECR/LANIE, 91191 Gif-sur-Yvette Cedex, France \\ ${ }^{\mathrm{b}}$ Commissariat à l'Energie Atomique, Saclay, DEN/DPC, France
}

\section{A R T I C L E I N F O}

\section{Article history:}

Received 19 April 2011

Received in revised form

15 September 2011

Accepted 15 September 2011

Available online 23 September 2011

\section{Keywords:}

Europium

TIMS

Channeltrons

Total evaporation

Isotope ratio

\begin{abstract}
A B S T R A C T
Thermal ionization mass spectrometry (TIMS) is a well established instrumental technique for providing accurate and precise isotope ratio measurements for elements with low first ionization potential. In the nuclear domain, particularly for the study of spent nuclear fuel sample solutions, the reduction of quantities is an important issue in order to decrease the analyst exposition to the radioactive samples. This paper presents experimental results obtained for picogram quantities of samples using electron multipliers (Channeltrons) implanted on the new generation of TIMS associated with the total evaporation (TE) acquisition method. TE method presents some advantages for the measurement of low quantities of samples in relation to the whole sample consumption and the integration of the whole signal. For this study, a Thermal Ionization Mass Spectrometer from IsotopX (Isoprobe-T) equipped with a multicollector system including Faraday cups and four movable Channeltrons is used. This work is focused on lanthanide elements, and particularly europium, in relation to the importance of their characterization in the spent fuel to validate neutronic calculation codes. In a first approach, europium isotopic ratios by total evaporation method using Faraday cups are obtained for quantities down to $250 \mathrm{pg}$. The results obtained by TE (Faraday cups only) on such low quantities confirm the potentialities of the method. A reproducibility of $2.5 \%$ o $(k=2)$, was obtained on the ${ }^{153} \mathrm{Eu} /{ }^{151} \mathrm{Eu}$ ratio $(n=11)$, for natural samples with an accuracy around $1 \%$.

In a second approach the same procedure is tested on Channeltron detectors by reducing the amounts of samples (from $50 \mathrm{pg}$ to $1 \mathrm{pg}$ ). In order to obtain accurate isotope results, intrinsic parameters such as applied voltages, dead time and noise were determined. A Channeltron specific intercalibration gain method was also developed, as this parameter was found to be the major source of uncertainties using this type of detectors. The reproducibility on the ${ }^{153} \mathrm{Eu} /{ }^{151} \mathrm{Eu}$ ratio was respectively found around $3 \%$ $(k=2)$. These results show the potentialities of isotopic measurements of sub-nanograms quantities and the different sources of uncertainties using total evaporation and Channeltrons on the Isoprobe-T.
\end{abstract}

(c) 2011 Elsevier B.V. All rights reserved.

\section{Introduction}

Thermal ionization mass spectrometry (TIMS) is a recognized technique for the determination of lanthanides on a broad range of samples [1-7]. For several years, many advances have been made for isotopic determination of lanthanides to improve analytical precision for very low quantities of element (few nanograms and lower) [8-10]. In nuclear industry the reduction of quantities is an important issue in order to minimize the analyst's exposure to the radiation of the samples. Concerning TIMS, many studies have focused on the enhancement of the ionization efficiency. These

\footnotetext{
* Corresponding author. Tel.: +3316908 8079.

E-mail address: helene.isnard@cea.fr (H. Isnard).
}

methods aim to reduce the oxide formation by understanding the associated mechanisms [11], improve beam focus and ion transmission by reducing the spatial extent of the sample load, or enhance the work function of the ionization filament (see for a review [12]). Instead of the measurement of lanthanide metallic ion, several authors use lanthanide single oxide ion measurements using $\mathrm{O}_{2}$ or different oxide activators on filaments [8,9,13-15] increasing therefore the ionization efficiency. Another major development for low quantity measurements is the use of photomultipliers, hybrid detector like Daly electrode [16], or electron multipliers (EM). The latter can be divided in two categories: discrete dynodes EM and continuous dynode EM (channel electron multipliers or Channeltrons). Since the original idea suggested by Farnsworth [17] to create this type of detector and their conception [18,19], several channel electron multiplier characteristics have been improved. 
Channeltrons, which were generally implanted in axial position, are now movable due to their miniaturized size on the new generation of TIMS [20-23]. In addition, data acquisition methods have been significantly improved. In order to achieve a suitable precision on isotope ratios [6], multistatic measurements using Faraday cup detectors associated with an internal normalization are traditionally used. Another method, called total evaporation (TE) [24], extensively used in the nuclear domain, was originally developed as an instrumental mass fractionation correction technique. The assumption made is that mass fractionation is minimized using total evaporation of the sample [4,10,25-29]. Another significant advantage of this technique is that very low amounts of samples are required [10].

The objective of this work is to study the potentialities and limitations of the TE method associated with Channeltron electron multipliers for low quantities europium isotopic ratio measurements. Europium was chosen in relation to its natural isotopic ratio close to $1\left({ }^{153} \mathrm{Eu} /{ }^{151} \mathrm{Eu}=1.0916 \pm 0.0019\right)$ [30] and because of its interest for nuclear applications [31,32]. The first part of this paper presents the optimization of the Channeltron parameters. A detailed description of the settings for this type of detector and a method for dead time determination will be presented. Then, investigations on low sample amounts will be presented in two steps. First, a data set was collected using total evaporation method on Faraday cups in order to obtain reference values (sample amounts down to $250 \mathrm{pg}$ ). In a second step, the method was transposed on Channeltrons in static multicollection mode for picogram quantities of sample. Reproducibility, accuracy and major sources of uncertainties on such low amounts will be discussed.

\section{Experimental}

\subsection{Reagents}

For the optimization of Channeltron parameters, uranium NIST 500 standard solutions from the National Institute of Standard and Technology (NIST) starting for $\mathrm{U}_{3} \mathrm{O}_{8}$ powder dissolved in $\mathrm{HNO}_{3}$ $14 \mathrm{M}$ are used. These solutions are re-concentred at $2 \mu \mathrm{g} / \mu \mathrm{L}$ using sub-boiling $\mathrm{HNO}_{3} 0.5 \mathrm{M}$. This acid was obtained by dilution of subboiling $14 \mathrm{M}$ nitric acid, using an EVAPOCLEAN system (Analab, France) and deionized water (resistivity $18.2 \mathrm{M} \Omega \mathrm{cm}$ ) obtained from a Milli Q system (Millipore, Milford, MA, USA).

Europium solutions are prepared from a NIST SRM 3117a sealed borosilicate glass ampoule diluted in $\mathrm{HNO}_{3}$ sub-boiling $0.5 \mathrm{M}$ in order to obtain $1,0.5$ and $0.25 \mathrm{ng} / \mu \mathrm{L}$ solutions for Faraday cup measurements and $50,25,10,5$ and $1 \mathrm{pg} / \mu \mathrm{L}$ solutions for Channeltron measurements. The concentrations of these solutions were checked using an X series Inductively Coupled Plasma Quadruple Mass Spectrometer (ICP-QMS) (Thermo Electron, Winsford, UK). For inter-Channeltron gain measurements, europium solution $(1 \mu \mathrm{g} / \mu \mathrm{L})$ in $2 \% \mathrm{HNO}_{3}$ from certified natural solutions (SPEX CertiPrep) is used.

\subsection{Instrumentation}

All the measurements were carried out on an Isoprobe-T, developed by IsotopX (Manchester, UK). This spectrometer is equipped with a glove box. A triple Re-filament configuration is used to control independently the evaporation and the ionization temperatures. This triple configuration is constituted of three filaments positioned in central, inside and outside positions. These filaments (thickness $30 \mu \mathrm{m}$, width $0.7 \mathrm{~mm}$ ), provided by ATES (Castelnau Le Lez, France), are obtained from a 99.995\% pure Re alloy. All filaments are beforehand degassed under a $10^{-7}$ mbar vacuum by warming up at different currents (respectively 1-3 A during $30 \mathrm{~min}$ then 4 and 5 A during $1 \mathrm{~h}$ each). $1 \mu \mathrm{L}$ of diluted solutions (described in Section 2.1) are deposited on the outside Re filament. During the deposit, the filament is heated up to $0.8 \mathrm{~A}$. Then the current is progressively increased to 2 A during $10 \mathrm{~s}$.

The analyzer is a low resolution magnetic field (resolution around 400). The multicollector is equipped with 9 movable Faraday cups, a fixed Daly electrode and 4 movable Channeltrons. Faraday cups are equipped with high-ohmic resistors $\left(10^{11} \Omega\right)$. The amplifiers are maintained at a low pressure $\left(10^{-2} \mathrm{mbar}\right)$ and at a constant temperature $\left(16^{\circ} \mathrm{C}\right)$ in a box, called Decabin, in order to reduce the Johnson noise. A WARP Filter (Wide Aperture Retarding Potential) is located before the electrode to improve abundance sensitivity [33] down to the ppb level. Four independently movable Channeltrons are located in low positions relative to the axial Faraday cup but only two of these (L4 and L5) were used in this study. The saturation level of these detectors is around 200,000 cps (counts per second). As these detectors are not equipped with any filters, abundance sensitivity was evaluated around 2 ppm as proportion of ${ }^{238} \mathrm{U}$ ion ion measured at mass 237 , in accordance to literature data [34].

\subsection{Channeltron optimization}

\subsubsection{Applied voltages}

On this instrument three parameters have to be optimized for each Channeltron: multiplier voltage (MV), discriminator voltage (DV), and entrance voltage (EV). MV is the voltage applied between the input and the output of the detector; DV reduces the dark noise (when no signal is applied) and has also an influence on the measured intensities. EV corrects for asymmetrical peak shape due to the incidence angle of the ion beam with the Channeltron. There is a last common parameter: CT Suppressor (CT Sup), which is used to prevent both electrons escaping from Channeltrons and stray electrons entrance, has to be determined. As no significant influence on signal intensities was observed for different CT Sup values, according to manufacturer recommendations, CT Sup was fixed at $-90 \mathrm{~V}$ for this study.

First, the multiplier voltage is optimized with DV set up to default values defined by the constructor (around $0.9 \mathrm{~V}$ ). A rhenium filament is heated up in order to have an ${ }^{187} \mathrm{Re}$ signal around 100,000 cps on the Daly electrode. This ion beam is then measured on Channeltron and MV is increased gradually in order to reach the optimum signal intensity. Both dark noise and Channeltron response are measured for each MV value. Fig. 1a shows the Channeltron response with respect to MV, whereas no significant dark noise variation was measured. An intensity plateau is observed between 2.6 and $2.9 \mathrm{kV}$. In order to optimize the detector life MV has to be set above the "knee" [35] (Fig. 1a). The optimized voltage is $2.6 \mathrm{kV}$ for L4 and $2.7 \mathrm{kV}$ for L5. This voltage has to be readjusted with respect to the detector behaviour.

The optimum DV is then set up when maximal intensity and minimal noise are obtained. The noise is measured when the isolation valve is closed. Fig. 1b shows that the optimal signal to noise ratio is obtained for a $\mathrm{DV}$ value close to $0.7 \mathrm{~V}$ for the $\mathrm{L} 5$ detector. The same approach lead to an optimum DV value of $1.2 \mathrm{~V}$ for the $\mathrm{L} 4$ detector.

EV is therefore optimized by using an automatic peak flat test implemented on the instrument software. EV is optimized by comparison of signal intensities at the peak centre (PKC) and on the both sides of the peak centre. EV is then fixed when all intensities are in the range $0.995<I / I_{\mathrm{PKC}}<1.005$. Following this procedure EV voltage is $-17 \mathrm{~V}$ for $\mathrm{L} 4$ and $-33 \mathrm{~V}$ for L5. As Channeltron peak shapes are dependent on the ion velocity and detector position, this set up has to be readjusted when a new element is analyzed or a new detector configuration is used. 

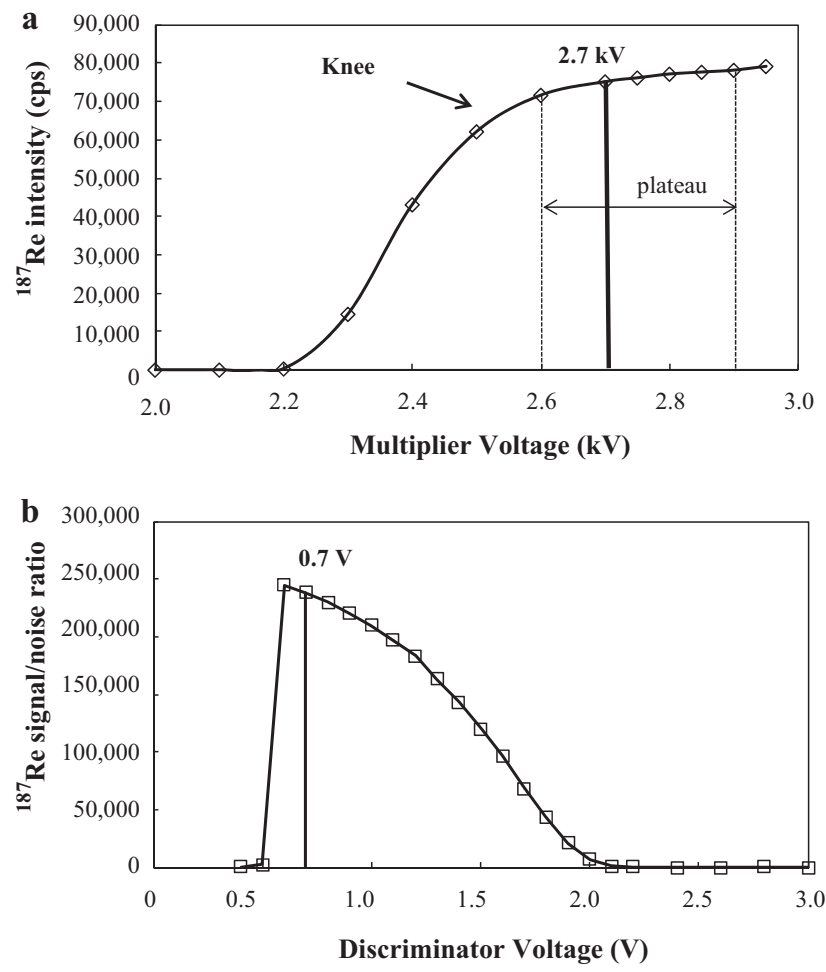

Fig. 1. Optimization of the multiplier voltage and discriminator voltage for the Channeltron L5. (a) ${ }^{187}$ Re signal intensity from the filament expressed in count per second (cps) versus multiplier voltage $(\mathrm{kV})$. The optimum value is obtained on the plateau (just above the "knee") and (b) ${ }^{187}$ Re signal to noise ratio versus discriminator voltage $(\mathrm{V})$. The optimized value is determined when the maximum ratio signal/noise is obtained.

\subsubsection{Dead time optimization}

Dead time, the minimum time interval required to detect independently two ions arriving at an electron multiplier, can impact the observed ratio to a varying degree depending on the count rate [36-39]. The following formula is traditionally used to apply dead time correction $[40,41]$ :

$I_{\text {corrected }}=\frac{I_{\text {measured }}}{1-\tau I_{\text {measured }}}$

where $\tau$ is the dead time, $I_{\text {corrected }}$ the dead time corrected intensity and $I_{\text {measured }}$ the measured signal intensity. An accurate and precise determination of the dead time prevents any signal losses and some non linearity effects $[37,42]$.

In this study the dead time calculation is performed following the method described by Vanhaecke et al. [43]. Experimentally, uranium certified standard NIST 500 was chosen because it has two certified uranium isotope ratios. ${ }^{235} \mathrm{U} /{ }^{238} \mathrm{U}$ is close to unity $\left({ }^{235} \mathrm{U} /{ }^{238} \mathrm{U}=0.9997 \pm 0.0014\right)$ and can be used for accurate mass-fractionation correction whereas ${ }^{234} U /{ }^{238} U$ ratio $=0.01042 \pm 0.00002$ can be used for dead-time evaluation. A specific acquisition method was used for this purpose: (1) Channeltron dead time is set initially at $0 \mathrm{~ns}$; (2) ${ }^{234} \mathrm{U}$ is measured on the studied Channeltron and (3) ${ }^{238} \mathrm{U}$ and ${ }^{235} \mathrm{U}$ are measured on Faraday cups. Then, the ratio ${ }^{234} \mathrm{U} /{ }^{238} \mathrm{U}$ is determined at increasing ${ }^{234} U$ signal intensities: $1 \times 10^{4}, 5 \times 10^{4}, 1 \times 10^{5}, 1.5 \times 10^{5}$ and $1.75 \times 10^{5} \mathrm{cps}$. Then, for each intensity rate on the Channeltron, relative isotope ratios were plotted as a function of the values used for the dead time correction leading to curves with a point of intersection as shown in Fig. 2a. The intersection of lines gives the experimentally determined dead time value. In our case, dead time was estimated at $150 \mathrm{~ns}$ for L4 and $290 \mathrm{~ns}$ for L5. Comparing to SEM or Daly electrode classical dead time values ( $\tau=10-50 \mathrm{~ns}$ )
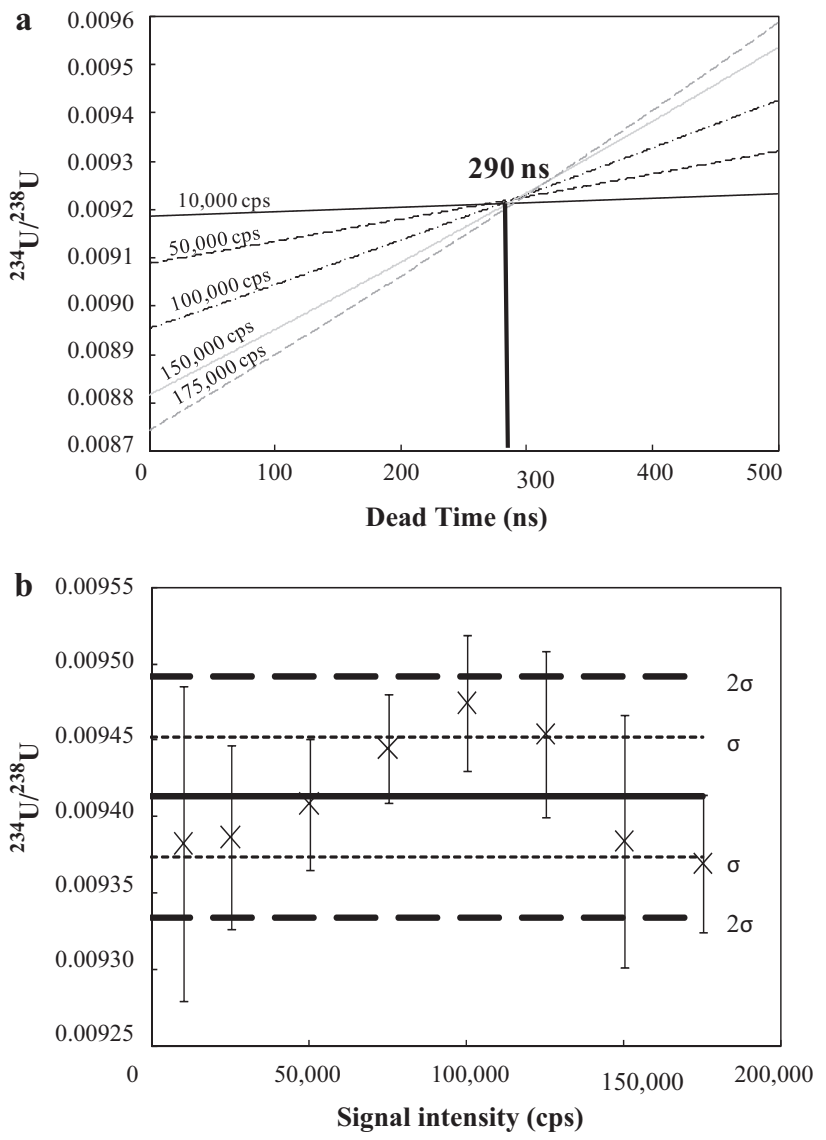

Fig. 2. Dead time and test of linearity for the Channeltron $L 5$ performed on uranium NIST 500. (a) ${ }^{234} U /{ }^{238} U$ isotope ratio (given in atom ratio) versus dead time values for different signal intensities. The intersection of the plots gives the optimum dead time. (b) Example of linearity test performed on ${ }^{234} \mathrm{U} /{ }^{238} \mathrm{U}$ isotope atom ratio (no gain correction) at different intensities of the ion beam. The solid line represents the mean of these measurements and the thin and thick dashed lines represent respectively the mean $\pm \sigma$ and the mean $\pm 2 \sigma$. It shows no discernible trend with the signal at the uncertainty of the measurements.

[35,44,45], the ones obtained for Channeltrons are much higher, which was already observed for this kind of detector $[43,46]$.

Several linearity tests are performed for each Channeltron on uranium NIST 500 standards in order to validate the above determined dead time values [35]. The linearity of the detector is characterized by an invariance of the measured isotopic ratio whatever signal intensity collected. Experimentally, ${ }^{238} \mathrm{U}$ is measured on a Faraday cup and ${ }^{234} \mathrm{U}$ on a Channeltron. Measurements are performed, like for the dead time optimization, at different ion currents without any gain corrections. Fig. $2 \mathrm{~b}$ shows an example of linearity test performed for a Channeltron. For both L4 and L5, the results demonstrate that the two detectors are linear from $5000 \mathrm{cps}$ to $175,000 \mathrm{cps}$. For each linearity test, the average of eight measurements (from $5000 \mathrm{cps}$ to $100,000 \mathrm{cps}$ ) is given with a reproducibility $<1 \%$.

\subsubsection{Noise and efficiency}

Noise measurements were performed, with closed isolation valve, on both detectors (L4 and L5). Each measurement takes around $20 \mathrm{~min}$ and the integration time is fixed at $5 \mathrm{~s}$ for a sequence. A noise level of about $0.2 \mathrm{cps}$ (counts per second) for $\mathrm{L} 4$ and $0.3 \mathrm{cps}$ for L5 was observed.

Finally, efficiencies of Channeltrons compared to were estimated at around 95\% for europium standard and around $70 \%$ for Uranium. These measurements performed by comparing a similar ion beam on both detectors (close to $1 \times 10^{5} \mathrm{cps}$ ) show that the 
efficiency of this kind of detectors decreases when the ratio $\mathrm{m} / \mathrm{z}$ increases.

\subsection{Total evaporation methods}

The "total evaporation" method, described first by Romkowski et al. [24] is based on the collection and integration of the overall ion beams generated by the total evaporation of a small sample amount in a short time. This method was initially developed in order to circumvent mass fractionation induced by thermal ionization sources [4,10,25-27].

A total evaporation analysis can be divided in 3 parts: adjustment, acquisition and shutdown phases [4]. For each step, some parameters are changed following the sample amount or the kind of detector. In the next part, the acquisition parameters used in the case of multi-collection mode with Faraday cups and Channeltrons is described. The advantage of this collection mode is to take account the ion beam fluctuations.

\subsubsection{Multi-static Faraday cup measurements}

First, Faraday cups are moved in order to collect the europium isotopes and intercalibration gains are measured daily by an automatic process. This is carried out using a highly stable current which is successively applied to each amplifier. Reproducibility of electronic gains obtained by this procedure was better than $0.001 \%$. The adjustment phase is the same for all the measurements done on Faraday cups whatever the quantity of sample deposited. During this step, filaments are gradually pre-heated at $4.5 \mathrm{~A}$ for the centre and $0.7 \mathrm{~A}$ for the side in $10 \mathrm{~min}$. The ionization filament temperature is then adjusted for a $80 \mathrm{mV}$ signal on the ${ }^{187} \mathrm{Re}$ ion beam. At this stage, peak centre and lens focus are performed and the centre filament temperature is kept constant during the overall analysis. Then, the side temperature is increased to reach a $5 \mathrm{mV}$ signal on the ${ }^{153} \mathrm{Eu}$ ion beam. This ion current is the minimum value required to perform a peak centre. No focus is performed on the ${ }^{153} \mathrm{Eu}$ to avoid further signal loss.

The acquisition phase begins with a peak centre measurement. Baselines are measured at $\pm 0.5 \mathrm{u}$ with a $5 \mathrm{~s}$ integration time. Then several parameters are modified in relation to the quantity of sample deposited on the filament. The aiming signal intensity (maximal instantaneous collected ion intensity) is set by the operator. The selected values are $1 \mathrm{~V}$ on the major isotope for samples ranging from $50 \mathrm{ng}$ to $100 \mathrm{ng}$ and $0.050 \mathrm{~V}$ for $1 \mathrm{ng}$ and lower sample amounts (called in the following "low quantity sample"). Each isotope is collected with an integration time of $10 \mathrm{~s}$ for $100-50 \mathrm{ng}$ samples and $5 \mathrm{~s}$ for low quantity samples. Continuous monitoring of the ion current decay rate governs the side filament temperature steps. The maximum side filament current is set at $4 \mathrm{~A}$ whatever the sample analyzed. The termination signal condition, which is the ion current intensity for the major isotope below which the analysis is stopped, is set at $5 \mathrm{mV}$ for all samples. Then, the shutdown phase, during which filament currents are set at $0 \mathrm{~A}$. Gain and baseline corrections are performed for each integration. Then the isotopic ratio is calculated on the basis of the integrated ion current for each isotope.

\subsubsection{Multi-static Channeltron measurements}

The acquisition procedure described above has to be adapted for the multi-static Channeltron measurements. The modifications applied are described below.

2.4.2.1. Intercalibration gain method. Channeltrons are moved in order to collect europium ion beams but, in opposition to Faradays cups, no automatic procedure is available to evaluate the relative detector response. A procedure was then developed for Channeltron gain calibration. In a first step, the ionization filament
Table 1

Successive sequences used to measure intercalibration gain on Channeltrons.

\begin{tabular}{lll}
\hline Channeltron & L4 & \multicolumn{1}{c}{ L5 } \\
\hline Sequence 1 & ${ }^{151} \mathrm{Eu}$ & - \\
Sequence 2 & ${ }^{153} \mathrm{Eu}$ & ${ }^{151} \mathrm{Eu}$ \\
Sequence 3 & - & ${ }^{153} \mathrm{Eu}$ \\
\hline
\end{tabular}

is gradually heated to $4.5 \mathrm{~A}$. Successive peak centre, lens focus, and ionization filament temperature adjustments are performed in order to obtain a $80 \mathrm{mV}$ signal on the ${ }^{187} \mathrm{Re}$ ion beam measured on Faraday cup. In a second step, the side filament temperature is adjusted to obtain a ${ }^{153} \mathrm{Eu}$ signal of $100,000 \mathrm{cps}$ on Channeltron. Peak centre, lens focus and baselines $( \pm 0.5 \mathrm{u})$ are performed before gain acquisition ( $5 \mathrm{~s}$ integration time). Data are acquired in multidynamic collection mode with three measurements sequences (see Table 1 ). The procedure includes 4 blocks of 10 cycles. Gains are calculated by sequential ${ }^{151} \mathrm{Eu}$ and ${ }^{153} \mathrm{Eu}$ signal measurements on Channeltron following Eq. (2):

$G_{L x / L y}(i)=\frac{\left({ }^{i} \mathrm{Eu}\right)_{L x}}{\left({ }^{i} \mathrm{Eu}\right)_{L y}}$

where $i$ stands for the considered europium isotope, $x$ and $y$ stand for the considered Channeltrons. This procedure is applied before and after each analysis. Gain values and reproducibilities will be discussed in Section 3.

2.4.2.2. Total evaporation using Channeltrons. In order to avoid preemitting signal on Eu no current was applied on side filaments while the centre filament is warmed up at $4.5 \mathrm{~A}$. The ${ }^{187} \mathrm{Re}$ ion beam is still optimized and focused at $80 \mathrm{mV}$ on a Faraday cup. The side filaments are then heated to reach a ${ }^{153} \mathrm{Eu}$ ion beam of $5000 \mathrm{cps}$ on Channeltron. Peak centre and baseline measurements are performed before the beginning of the acquisition phase. During this step ion beams are collected ( 5 s integration time) on both Channeltrons ( ${ }^{151} \mathrm{Eu}$ on L5 and ${ }^{153} \mathrm{Eu}$ on L4) with an aiming intensity sets at $100,000 \mathrm{cps}$. The maximum side filament current is set at $4 \mathrm{~A}$. The termination intensity is fixed at $5000 \mathrm{cps}$. The shutdown phase is already described in Section 2.4.1.

\section{Results and discussion}

\subsection{Multi-static Faraday cup measurements}

Natural europium isotopic measurements have been performed by TE method during several years in our Laboratory (50-100 ng deposits, $n=34$ ). For 26 measurements the cumulated ${ }^{153} \mathrm{Eu}$ signals are included between 50 and $200 \mathrm{~V}$. Four measurements have a cumulated ${ }^{153} \mathrm{Eu}$ signal $<50 \mathrm{~V}$ and four values are above $200 \mathrm{~V}$. Two values were rejected after performing a statistical test on the ${ }^{153} \mathrm{Eu} /{ }^{151} \mathrm{Eu}$ measured ratios. The average value obtained on these 32 measurements is $1.0927 \pm 0.0011(k=2)$ which is consistent with IUPAC reference value $1.0916 \pm 0.0019$ for natural europium $[1,30]$ within uncertainties. During this work, ten measurements were performed with a $1 \mathrm{ng}$ deposit with cumulated ${ }^{153} \mathrm{Eu}$ signals ranging from 0.3 to $20 \mathrm{~V}$ ( 1 rejection). Six measurements were performed with a $0.5 \mathrm{ng}$ deposit and the collected ${ }^{153} \mathrm{Eu}$ signals ranging from 0.2 and $7 \mathrm{~V}$ (no rejection) for these analyses. Eleven measurements were performed with a $0.25 \mathrm{ng}$ deposit with cumulated ${ }^{153} \mathrm{Eu}$ signals ranging from 0.2 to $1.5 \mathrm{~V}$ ( 1 rejection). The average ${ }^{153} \mathrm{Eu} /{ }^{151} \mathrm{Eu}$ values obtained by TE for lower quantities: $1 \mathrm{ng}, 0.5 \mathrm{ng}$ and $0.25 \mathrm{ng}$ are respectively equal to $1.0928 \pm 0.0011(k=2, n=9)$, $1.0931 \pm 0.0005(k=2, n=6)$ and $1.0939 \pm 0.0027(k=2, n=10)$. The results obtained are all consistent with the laboratory reference value within uncertainty (Fig. 3a). As expected, a higher reproducibility is observed for the lowest amounts of sample $(0.25 \mathrm{ng})$. 

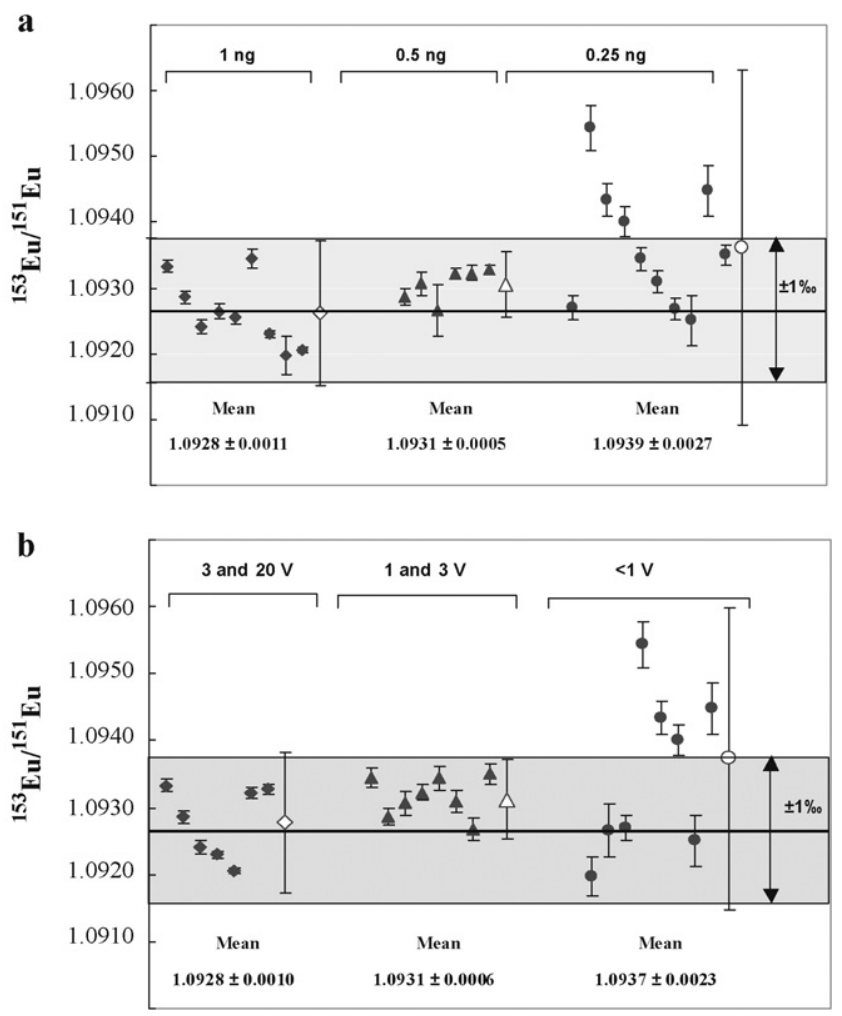

Fig. 3. Results of TE method for ${ }^{151} \mathrm{Eu} /{ }^{153} \mathrm{Eu}$ ratio (given in atom ratio) for samples of $250 \mathrm{pg}$ to $50 \mathrm{ng}$ of europium NIST standard solution using static multicollection mode with Faraday cup detectors. Each data point is represented with an uncertainty applying the counting statistic $\sigma N=\sqrt{N} / N$, where $N$ is the number of ions. Dash area corresponds to the reference value obtained for quantity of $50 \mathrm{ng}$ $\left({ }^{151} \mathrm{Eu} /{ }^{153} \mathrm{Eu}=1.0927 \pm 0.0011\right)$. (a) The data are represented based on the mass of deposit on the filament. The mean values of each data series are indicated with their uncertainties expressed as the standard deviation at a confident level of $k=2$. (b) The data are represented based on total signal collected during the analysis. The mean values of each data series are indicated with their uncertainty expressed as the standard deviation at a confident level of $k=2$.

Fig. 3b shows the ${ }^{153} \mathrm{Eu} /{ }^{151} \mathrm{Eu}$ ratio versus cumulated ${ }^{153} \mathrm{Eu}$ signal. We observed a significant increase of the standard deviation when cumulated ${ }^{153}$ Eu signal decreases. As observed in Fig. 3b, a cumulated ${ }^{153} \mathrm{Eu}$ signal close to $1 \mathrm{~V}$ is required in order to obtain a reproducibility $(k=2)$ of $1 \%$.

\subsection{Multi-static Channeltron measurements}

\subsubsection{Intercalibration gains and uncertainty}

As described in Section 2.4.2, Channeltron-Channeltron intercalibration gain must be carefully determined in order to obtain accurate isotope ratio. Several tests were conducted to evaluate the intercalibration gain dependence with respect to the atomic mass of the studied element. Several elements (K, Mo, Eu, Re, U) were tested for this purpose. A clear decrease of the L4/L5 gain is observed with increasing $m / z$. This phenomenon is ascribed to detection efficiency dependence with respect to ion mass, incidence angle, ion charge and velocity [47]. However, no significant variation linked to this phenomenon was observed for the two europium masses ( $151 \mathrm{u}$ and $153 \mathrm{u}, \Delta M=2 \mathrm{u}$ ) and the average of gains calculated on each isotope is determined.

As indicated in Section 2.4.2, average gain (i.e. average gain value before and after analysis) is used for measurement corrections in order to account for time variations (following Eq. (3)):

$G_{L x / L y}=\frac{\left(G_{L x / L y}\right)_{t 1}+\left(G_{L x / L y}\right)_{t 2}}{2}$

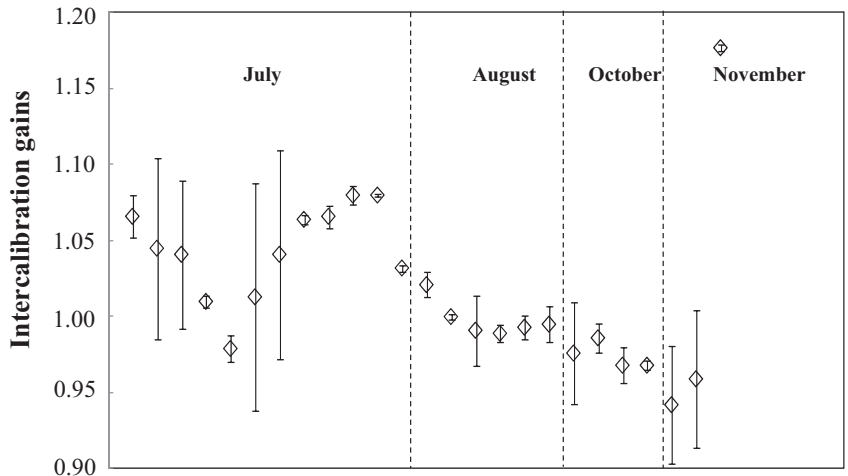

Fig. 4. Evolution of the gain values during the examined time period, July through November. Each interval included between the two vertical lines represents one day. Each gain is indicated with its uncertainty expressed as standard deviation at a confident level of $k=1$. The uncertainties are evaluated by the relative difference of the gain value before and after measurements of the sample.

where $G_{L x / L y}$ stands for average gain, $\left(G_{L x / L y}\right)_{t 1}$ is the gain before the analysis and $\left(G_{L x / L y}\right)_{t 2}$ is the gain after analyses.

Gain repeatability ranges between 0.03 and $0.2 \%$. As shown in Fig. 4, where average gain variations obtained for 25 analyses performed during 5 months are reported, long term gain reproducibility $(n=25)$ was found to be close to $5 \%(k=1)$. To take into account this reproducibility, we evaluated the relative gain difference before and after measurement following Eq. (4):

$\Delta G=\frac{\left(G_{L x / L y}\right)_{t 1}-\left(G_{L x / L y}\right)_{t 2}}{G_{L x / L y}}$

Final uncertainty on intercalibration gain was evaluated by combination of this relative gain difference and repeatability.

\subsubsection{Total evaporation measurements}

Several measurements using TE method with europium quantities varying from $100 \mathrm{pg}$ to $1 \mathrm{pg}$ and Channeltron detection were performed. $100 \mathrm{pg}$ measurements were stopped due to a long analysis time $(>1 \mathrm{~h})$. By consequence only measurements ranging from $50 \mathrm{pg}$ to $1 \mathrm{pg}$ were really studied. The same acquisition method was used whatever the quantity deposited on the side filament.

The profiles observed by TE using Channeltron detector are comparable to those obtained using Faraday cup with the exception of very low quantity $(1-10 \mathrm{pg})$ profiles which are very short transient signals. A pre-emitting ion beam (i.e. a short transient europium signal) in the beginning of peak integration was also observed for the large majority of data although side filaments are not heated up. This could be explained by the fact that the centre filament alone produces enough energy to partially evaporate and ionise europium on the side filament.

Table 2 reports the results obtained for each deposited quantity. The data are ordered in relation to the cumulated ${ }^{153} \mathrm{Eu}$ count rate $\left(>10^{7} \mathrm{cps}\right.$, between 1 and $10^{7} \mathrm{cps}$ and $<10^{6} \mathrm{cps}$ ). Intercalibration gain and associated uncertainty are also reported together with raw and corrected ${ }^{153} \mathrm{Eu} /{ }^{151} \mathrm{Eu}$ ratio. Uncertainty on raw ratios is evaluated by applying the counting statistic $\sqrt{N} / N$, where $N$ is the number of ions [10]. The corrected ${ }^{153} \mathrm{Eu} /{ }^{151} \mathrm{Eu}$ ratio uncertainty is expressed taking into account the combination of raw ratios and gain uncertainty (see Section 3.2.1). The ${ }^{153} \mathrm{Eu} /{ }^{151} \mathrm{Eu}$ ratio average value and relative standard deviation (RSD) (varying from $0.85 \%$ to $1.85 \%$ ) were estimated for each cumulated count rate range (Fig. 5). Uncertainty calculation shows that the gain uncertainty (\% range) budget is the major source of uncertainty for static collection mode measurements using Channeltrons. The average value obtained for 25 measurements on the ${ }^{153} \mathrm{Eu} /{ }^{151} \mathrm{Eu}$ ratio $=1.0920(3.3 \%, k=2)$. This value is in good agreement (accuracy ranging from $0.5 \%$ to 
Table 2

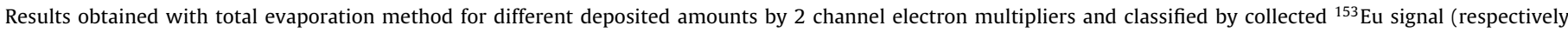

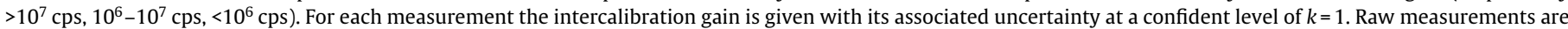

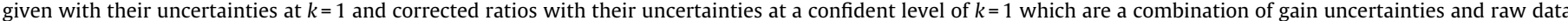
uncertainties. Their means are given with the standard deviation at a confident level of $k=2$.

\begin{tabular}{|c|c|c|c|c|c|c|c|}
\hline Deposit (pg) & $\begin{array}{l}\text { Cumulated } \\
\text { count rate } \\
{ }^{153} \mathrm{Eu} \text { (cps) }\end{array}$ & Gain & Uncertainty \% $(k=1)$ & ${ }^{153} \mathrm{Eu} /{ }^{151} \mathrm{Eu}$ raw & Uncertainty $\%(k=1)$ & ${ }^{153} \mathrm{Eu} /{ }^{151} \mathrm{Eu}$ corr. & Uncertainty $\%(k=1)$ \\
\hline 50 & $1.3 \mathrm{E}+07$ & 1.07 & 1.3 & 1.1595 & 0.025 & 1.0881 & 1.3 \\
\hline 50 & $1.0 \mathrm{E}+07$ & 0.94 & 4.1 & 1.0067 & 0.029 & 1.0692 & 4.1 \\
\hline 50 & $9.8 \mathrm{E}+06$ & 0.96 & 0.5 & 1.0408 & 0.029 & 1.0853 & 0.5 \\
\hline 25 & $2.2 \mathrm{E}+07$ & 1.04 & 4.7 & 1.1384 & 0.020 & 1.0937 & 4.7 \\
\hline 25 & $6.3 \mathrm{E}+07$ & 1.04 & 6.6 & 1.1537 & 0.011 & 1.1087 & 6.6 \\
\hline \multirow[t]{5}{*}{10} & $3.7 \mathrm{E}+07$ & 1.01 & 7.4 & 1.0937 & 0.015 & 1.0795 & 7.4 \\
\hline & Mean & & & 1.0988 & & 1.0874 & \\
\hline & $2 S D$ & & & 0.1269 & & 0.0267 & \\
\hline & 2RSD \% & & & 12 & & 2.5 & \\
\hline & Accuracy (\%) & & & & & -0.5 & \\
\hline 50 & $2.0 \mathrm{E}+06$ & 1.08 & 0.6 & 1.1896 & 0.064 & 1.1019 & 0.6 \\
\hline 50 & $3.9 \mathrm{E}+06$ & 1.08 & 0.1 & 1.1968 & 0.046 & 1.1085 & 0.2 \\
\hline 25 & $4.2 \mathrm{E}+06$ & 1.05 & 5.7 & 1.1555 & 0.044 & 1.1060 & 5.7 \\
\hline 25 & $6.6 \mathrm{E}+06$ & 1.06 & 0.3 & 1.1804 & 0.035 & 1.1091 & 0.3 \\
\hline 25 & $4.0 \mathrm{E}+06$ & 1.07 & 0.7 & 1.1789 & 0.045 & 1.1061 & 0.7 \\
\hline 10 & $4.9 \mathrm{E}+06$ & 0.99 & 0.6 & 1.0934 & 0.041 & 1.1060 & 0.6 \\
\hline 5 & $2.0 \mathrm{E}+06$ & 0.99 & 2.3 & 1.0982 & 0.065 & 1.1086 & 2.3 \\
\hline 5 & $2.7 \mathrm{E}+06$ & 0.98 & 3.4 & 1.0627 & 0.056 & 1.0894 & 3.4 \\
\hline \multirow[t]{5}{*}{1} & $5.7 \mathrm{E}+06$ & 1.03 & 0.2 & 1.1530 & 0.037 & 1.1175 & 0.2 \\
\hline & Mean & & & 1.1278 & & 1.1059 & \\
\hline & $2 S D$ & & & 0.0992 & & 0.0184 & \\
\hline & 2RSD \% & & & 8.8 & & 1.7 & \\
\hline & Accuracy (\%) & & & & & 1.2 & \\
\hline 10 & $6.9 \mathrm{E}+05$ & 1.01 & 0.4 & 1.0634 & 0.11 & 1.0532 & 0.4 \\
\hline 10 & $9.9 \mathrm{E}+05$ & 0.99 & 0.8 & 1.0681 & 0.09 & 1.0753 & 0.8 \\
\hline 10 & $5.9 \mathrm{E}+03$ & 1.18 & 0.2 & 1.2905 & 1.18 & 1.0960 & 1.2 \\
\hline 5 & $9.3 \mathrm{E}+05$ & 1.00 & 0.2 & 1.1092 & 0.09 & 1.1093 & 0.2 \\
\hline 5 & $8.9 \mathrm{E}+05$ & 1.00 & 1.2 & 1.0850 & 0.10 & 1.0905 & 1.2 \\
\hline 5 & $5.2 \mathrm{E}+05$ & 1.02 & 0.8 & 1.0850 & 0.13 & 1.0629 & 0.8 \\
\hline 1 & $2.4 \mathrm{E}+05$ & 0.98 & 0.9 & 1.0718 & 0.19 & 1.0943 & 1.0 \\
\hline 1 & $7.3 \mathrm{E}+04$ & 0.99 & 1.0 & 1.0378 & 0.35 & 1.0525 & 1.1 \\
\hline 1 & $1.1 \mathrm{E}+05$ & 0.97 & 1.2 & 1.0622 & 0.27 & 1.0973 & 1.2 \\
\hline \multirow[t]{9}{*}{1} & $2.6 \mathrm{E}+04$ & 0.97 & 0.3 & 1.0568 & 0.57 & 1.0919 & 0.6 \\
\hline & Mean & & & 1.0930 & & 1.0823 & \\
\hline & $2 S D$ & & & 0.1440 & & 0.0400 & \\
\hline & 2RSD \% & & & 13.2 & & 3.7 & \\
\hline & Accuracy (\%) & & & & & -1.0 & \\
\hline & Mean, $n=25$ & & & & & 1.0920 & \\
\hline & 2SD & & & & & 0.0359 & \\
\hline & 2RSD \% & & & & & 3.3 & \\
\hline & Accuracy (\%) & & & & & -0.06 & \\
\hline
\end{tabular}

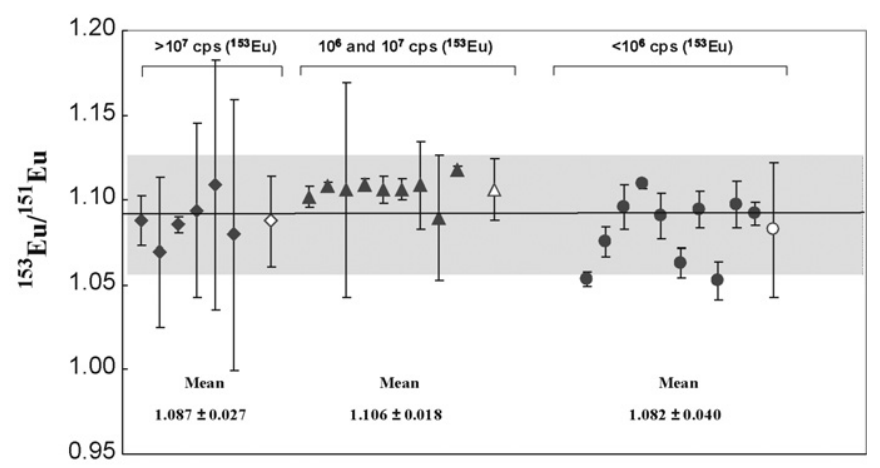

Fig. 5. Results of TE method and multistatic Channeltron detection for the ${ }^{153} \mathrm{Eu} /{ }^{151} \mathrm{Eu}$ ratio (given in atom ratio) with masses ranging from $1 \mathrm{pg}$ to $50 \mathrm{pg}$. The results are classified in three categories according to the collected signal on the ${ }^{153} \mathrm{Eu}$ isotope. Each value is given with its uncertainty which is a combination of the gain uncertainty and counting uncertainty based on Poisson statistic. Each white point represents the mean for each category with its uncertainty at a confident level of $k=2$. The solid line represents the reference value of the laboratory at $50 \mathrm{ng}$ and the gray area its uncertainty level.
$1.2 \%$ depending of the collected signal) with TE Faraday cup measurements within uncertainty.

So, Channeltrons allow the measurements of picogram size samples dividing by 1000 and more the traditional quantity (50 ng) deposited on the filament in comparison to measurements using Faraday cups. A potential application of this type of detector is to measure the Eu and lanthanides isotopic composition in irradiated fuel samples of limited sample size. For example in the case of lanthanide transmutation target [48] irradiated in French fast neutron reactor, the quantity of products formed are very low (ng to pg quantities). The TE method on channeltron electron multipliers may hold potential for applications in this research field. Nevertheless this type of detector involves an uncertainty increase due to (1) higher uncertainty of the ion counting statistic and (2) intercalibration gain reproducibility which is not better than \% level. However in several applications, Channeltrons could be used on peak jumping mode. For comparison at $100,000 \mathrm{cps}$ (which are performed on $\mathrm{L}_{4}$ detector) repeatability for europium measurements in peak jumping mode are around $0.2 \%$ ( 50 cycles, $k=1$ ) and reproducibility around $1.4 \%(n=5, k=2)$. 


\section{Conclusions}

This study presents the optimization of Channeltron detectors implanted on an Isoprobe-T (IsotopX, UK) Thermal Ionization Mass Spectrometer. All Channeltron parameters are studied and for each detector noise, efficiency and dead time are evaluated. This type of detector is used to obtain europium isotopic ratio measurements in static multicollection mode using TE. The average value on the ${ }^{153} \mathrm{Eu} /{ }^{151} \mathrm{Eu}$ ratio for 25 measurements with quantity deposit ranging from 1 to $50 \mathrm{pg}$ is equal at $1.092 \pm 0.036$ (SD at $k=2$ ) in agreement with reference value obtained on Faraday/Faraday static measurements $\left({ }^{153} \mathrm{Eu} /{ }^{151} \mathrm{Eu}=1.0927 \pm 0.0011\right)$. The major source of uncertainty for this type of measurements is related to the intercalibration gain uncertainty which vary between $0.1 \%$ and $7 \%$ during all the analytical session.

\section{References}

[1] T.L. Chang, Q.Y. Qian, M.T. Zhao, J. Wang, The absolute isotopic composition of europium, Int. J. Mass Spectrom. Ion Processes 139 (1994) 95-102.

[2] F. Chartier, M. Aubert, M. Salmon, M. Tabarant, B.H. Tran, Determination of erbium in nuclear fuels by isotope dilution thermal ionization mass spectrometry and glow discharge mass spectrometry, J. Anal. At. Spectrom. 14 (1999) 1461-1465.

[3] J.R. De Laeter, N. Bukilic, The isotopic composition and atomic weight of ytterbium, Int. J. Mass Spectrom. 252 (2006) 222-227.

[4] J.C. Dubois, G. Retali, J. Cesario, Isotopic analysis of rare-Earth elements by total vaporization of samples in thermal ionization mass-spectrometry, Int. J. Mass Spectrom. Ion Processes 120 (1992) 163-177.

[5] H. Isnard, R. Brennetot, C. Caussignac, N. Caussignac, F. Chartier, Investigations for determination of $\mathrm{Gd}$ and $\mathrm{Sm}$ isotopic compositions in spent nuclear fuels samples by MC ICPMS, Int. J. Mass Spectrom. 246 (2005) 66-73.

[6] G. Caro, B. Bourdon, J.L. Birck, S. Moorbath, High-precision Nd-142/Nd-144 measurements in terrestrial rocks: constraints on the early differentiation of the Earth's mantle, Geochim. Cosmochim. Acta 70 (2006) 164-191.

[7] G. Caro, B. Bourdon, A.N. Halliday, G. Quitte, Super-chondritic Sm/Nd ratios in mars, the earth and the moon, Nature 452 (2008) 336-339.

[8] Z.Y. Chu, F.K. Chen, Y.H. Yang, J.H. Guo, Precise determination of Sm, Nd concentrations and Nd isotopic compositions at the nanogram level in geological samples by thermal ionization mass spectrometry, J. Anal. At. Spectrom. 24 (2009) 1534-1544.

[9] J. Harvey, E.F. Baxter, An improved method for TIMS high precision neodymium isotope analysis of very small aliquots (1-10 ng), Chem. Geol. 258 (2009) 251-257.

[10] S. Wakaki, S. Shibata, T. Tanaka, Isotope ratio measurements of trace Nd by the total evaporation normalization (TEN) method in thermal ionization mass spectrometry, Int. J. Mass Spectrom. 264 (2007) 157-163.

[11] D. Alamelu, S.J. Kumar, A.R. Parab, A.K. Choudhary, S.K. Aggarwal, Studies on the formation of atomic and molecular ions of uranium and thorium in thermal ionization mass spectrometry, Int. J. Mass spectrom. 291 (2010) 140-144.

[12] S. Burger, L.R. Riciputi, D.A. Bostick, S. Turgeon, E.H. McBay, M. Lavelle, Isotope ratio analysis of actinides, fission products, and geolocators by high-efficiency multi-collector thermal ionization mass spectrometry, Int. J. Mass Spectrom. 286 (2009) 70-82.

[13] M. Griselin, J.C. van Belle, C. Pomies, P.Z. Vroon, M.C. van Soest, G.R. Davies, An improved chromatographic separation technique of Nd with application to NdO+ isotope analysis, Chem. Geol. 172 (2001) 347-359.

[14] C.F. Li, F.K. Chen, X.H. Li, Precise isotopic measurements of sub-nanogram Nd of standard reference material by thermal ionization mass spectrometry using the NdO+ technique, Int. J. Mass Spectrom. 266 (2007) 34-41.

[15] M.F. Thirlwall, High-precision multicollector isotopic analysis of low-levels of Nd as oxide, Chem. Geol. 94 (1991) 13-22.

[16] N.R. Daly, Scintillation type mass spectrometer ion detector, Rev. Sci. Instrum. 31 (1960) 264-267.

[17] Farnsworth, Electron multiplier US Patent 1,966,399 (1930).

[18] G.W. Goodrich, W.C. Wiley, Resistance strip magnetic electron multiplier, Rev. Sci. Instrum. 32 (1961) 846-849.

[19] G.W. Goodrich, W.C. Wiley, Continuous channel electron multiplier, Rev. Sci. Instrum. 33 (1962) 761-762.

[20] J.H. Barnes, G.M. Hieftje, Recent advances in detector-array technology for mass spectrometry, Int. J. Mass Spectrom. 238 (2004) 33-46.

[21] S. Richter, U. Ott, F. Begemann, Multiple ion counting in isotope abundance mass-spectrometry, Int. J. Mass Spectrom. Ion Processes 136 (1994) 91-100.

[22] R. Andreasen, M. Sharma, Fractionation and mixing in a thermal ionization mass spectrometer source: implications and limitations for high-precision $\mathrm{Nd}$ isotope analyses, Int. J. Mass Spectrom. 285 (2009) 49-57.
[23] R. Jakopic, S. Richter, H. Kuhn, L. Benedik, B. Pihlar, Y. Aregbe, Isotope ratio measurements of pg-size plutonium samples using TIMS in combination with multiple ion counting and filament carburization, Int. J. Mass Spectrom. 279 (2009) 87-92.

[24] M. Romkowski, S. Franzini, L. Koch, Mass-spectrometric analysis of subnanocurie samples of uranium and plutonium, in: 8th Annual ESARDA Symposium, Commission European Comm., London, 1987, p. 12.

[25] E.L. Callis, R.M. Abernathey, High-Precision isotopic analyses of uranium and plutonium by total sample volatilization and signal integration, Int. J. Mass Spectrom. Ion Processes 103 (1991) 93-105.

[26] R. Fiedler, Total evaporation measurements: experience with multi-collector instruments and a thermal ionization quadrupole mass-spectrometer, Int. J. Mass Spectrom. Ion Processes 146 (1995) 91-97.

[27] R. Fiedler, D. Donohue, G. Grabmueller, A. Kurosawa, Report on preliminary experience with total evaporation measurements in thermal ionization massspectrometry, Int. J. Mass Spectrom. Ion Processes 132 (1994) 207-215.

[28] S. Richter, S.A. Goldberg, Improved techniques for high accuracy isotope ratio measurements of nuclear materials using thermal ionization mass spectrometry, Int. J. Mass Spectrom. 229 (2003) 181-197.

[29] S. Richter, H. Kuhn, Y. Aregbe, M. Hedberg, J. Horta-Domenech, K. Mayer, E. Zuleger, S. Burger, S. Boulyga, A. Kopf, J. Poths, K. Mathew, Improvements in routine uranium isotope ratio measurements using the modified total evaporation method for multi-collector thermal ionization mass spectrometry, J. Anal. At. Spectrom. 26 (2011) 550-564.

[30] J.R. De Laeter, J.K. Bohlke, P. De Bievre, H. Hidaka, H.S. Peiser, K.J.R. Rosman, P.D.P. Taylor, Atomic weights of the elements: Review 2000 - (IUPAC technical report), Pure Appl. Chem. 75 (2003) 683-800.

[31] F. Gueguen, A. Nonell, M. Granet, G. Favre, H. Isnard, F. Chartier, Eu isotopic measurements with in situ $\mathrm{Eu} / \mathrm{Gd} / \mathrm{Sm}$ separation using $\mathrm{O}_{2}$ as a reactant gas in collision/reaction cell based MC-ICP-MS, J. Anal. At. Spectrom. 25 (2010) 201-205.

[32] C. Soderquist, B. Hanson, Dissolution of spent nuclear fuel in carbonate-peroxide solution, J. Nucl. Mater. 396 (2010) 159-162.

[33] A.D. McNaught, A. Wilkinson, IUPAC Compendium of Chemical Terminology, 2nd edition, 1997.

[34] M.E. Wieser, J.B. Schwieters, The development of multiple collector mass spectrometry for isotope ratio measurements, Int. J. Mass Spectrom. 242 (2005) 97-115.

[35] S. Richter, S.A. Goldberg, P.B. Mason, A.J. Traina, J.B. Schwieters, Linearity tests for secondary electron multipliers used in isotope ratio mass spectrometry, Int. J. Mass Spectrom. 206 (2001) 105-127.

[36] J.M. Hayes, D.A. Schoeller, High precision pulse counting: limitations and optimal conditions, Anal. Chem. 49 (1977) 306-311.

[37] J. Moser, W. Wegscheider, T. Meisel, Uncertainty of dead time estimation in ICP-MS, J. Anal. At. Spectrom. 18 (2003) 508-511.

[38] J.A. Williamson, M.W. Kendalltobias, M. Buhl, M. Seibert, Statistical evaluation of dead time effects and pulse pileup in fast photon-counting: introduction of the sequential model, Anal. Chem. 60 (1988) 2198-2203.

[39] H. Rameback, M. Berglund, D. Vendelbo, R. Wellum, P.D.P. Taylor, On the determination of the true dead-time of a pulse-counting system in isotope ratio mass spectrometry, J. Anal. At. Spectrom. 16 (2001) 1271-1274.

[40] G.F. Knoll, Chapter 4 general properties of radiation detectors, in: J.W. sons (Ed.), Radiation detection and measurements, New York (2000) 103-128.

[41] J.W. Muller, Dead-time problems, Nucl. Instrum. Methods 112 (1973) 47-57.

[42] S.M. Nelms, C.R. Quetel, T. Prohaska, J. Vogl, P.D.P. Taylor, Evaluation of detector dead time calculation models for ICP-MS, J. Anal. At. Spectrom. 16 (2001) 333-338.

[43] F. Vanhaecke, G. de Wannemacker, L. Moens, R. Dams, C. Latkoczy, T. Prohaska, G. Stingeder, Dependence of detector dead time on analyte mass number in inductively coupled plasma mass spectrometry, J. Anal. At. Spectrom. 13 (1998) 567-571.

[44] H. Cheng, R.L. Edwards, J. Hoff, C.D. Gallup, D.A. Richards, Y. Asmerom, The half-lives of uranium-234 and thorium-230, Chem. Geol. 169 (2000) 17-33.

[45] A. Gourgiotis, H. Isnard, M. Aubert, E. Dupont, I. AlMahamid, G. Tiang, L. Rao, W. Lukens, P. Cassette, S. Panebianco, A. Letourneau, F. Chartier, Accurate determination of Curium and Californium isotopic ratios by inductively coupled plasma quadrupole mass spectrometry (ICP-QMS) in Cm-248 samples for transmutation studies, Int. J. Mass Spectrom. 291 (2010) 101-107.

[46] R.M. Ellam, A.W. Tudhope, Uranium and thorium isotope ratio measurements using multiple collector inductively coupled plasma mass spectrometry with multi-ion-counting detectors, in: J.G. Holland, S.D. Tanner (Eds.), Plasma Source Mass Spectrometry: Applications and Emerging Technologies, Royal Soc Chemistry, Cambridge, 2003, pp. 391-403.

[47] Burle Electro-Optics Inc., Photonis, http://www.photonis.com/upload/ industryscience/pdf/electron_multipliers/ChannelBook.pdf, February 2010.

[48] H. Isnard, J. Moureau, S. Quidelleur, F. Gueguen, M. Granet, G. Favre, A. Nonell, F. Chartier, Attractive approach to analyse trace and ultra-trace elements on transmutation targets by direct separation of isobaric interferences using collision reaction cell implanted on MC-ICPMS, in: Advancements in Nuclear Instrumentation Measurement Methods and their Applications (ANIMMA), 2009, pp. 1-6. 